\title{
SISTEMA ELECTORAL, INVESTIDURA Y MOCIÓN DE CENSURA: TRES EJEMPLOS DE FLEXIBILIDAD CONSTITUCIONAL Y DE ARBITRISMO DOCTRINAL
}

\author{
ELECTORAL SYSTEM, CONFIDENCE AND NO-CONFIDENCE VOTE: THREE \\ EXAMPLES OF CONSTITUTIONAL FLEXIBILITY AND DOCTRINAL ARBITRISM
}

\author{
Manuel Alba Navarro \\ Cortes Generales
}

Cómo citar / Nola aipatu: Alba Navarro, M. (2020). Sistema electoral, investidura y moción de censura: tres ejemplos de flexibilidad constitucional y de arbitrismo doctrinal. Legebiltzarreko Aldizkaria - LEGAL - Revista del Parlamento Vasco, (1):12-39.

https://doi.org/10.47984/legal.2020.001

\section{RESUMEN}

Los cambios acaecidos en el sistema político español desde 2015 han afectado a su sistema de partidos, el cual ha cambiado sustancialmente. Ha quedado demostrada la versatilidad de la Constitución de 1978 y de su régimen electoral para permitir la transformación del sistema y, a la vez, hacer frente a la inestabilidad política. Sin embargo, estos cambios han disparado las propuestas doctrinales de reformas en este ámbito, desaconsejables en su inmensa mayoría.

\section{PALABRAS CLAVE}

Constitución, sistema electoral, sistema de partidos, ley electoral, reforma constitucional, Gobierno, Parlamento, investidura, moción de censura.

\section{ABSTRACT}

The changes that happened in spanish political system from 2015 did affect to the parties system, which has deeply changed. The versatility of 1978 Constitution (electoral system included) has been proved in order to allow this change and, at the same time, been capable to face political instability. Nevertheless these changes have shooted up reform proposals made by doctrine. Inadvisables most of them.

\section{KEYWORDS}

Constitution, Electoral system, parties system, electoral law, constitutional reform, Government, Parliament, confidence vote, no-confidence vote. 


\section{LABURPENA}

Espainiako sistema politikoan 2015etik izandako aldaketek eragina izan dute haren alderdi-sisteman, eta nabarmen aldatu da sistema hori. Frogatuta geratu da 1978ko Konstituzioaren eta haren hauteskunde-araubidearen aldakortasuna, sistema-aldaketa ahalbidetzeko eta, aldi berean, ezegonkortasun politikoari aurre egiteko. Hala ere, aldaketa horiek asko ugaritu dituzte esparru horretako erreformarako doktrina-proposamenak. Gehienak ez dira gomendagarriak.

\section{GAKO-HITZAK}

Konstituzioa, hauteskunde-sistema, alderdien sistema, hauteskunde-legea, Konstituzioaren erreforma, Gobernua, parlamentua, inbestidura, zentsura-mozioa.

\section{SUMARIO}

I. PLANTEAMIENTO.

II. LA IMPREVISTA FLEXIBILIDAD DEL SISTEMA ELECTORAL ESPAÑOL.

III. LA TRASLACIÓN DEL "PROBLEMA" A OTROS ÁMBITOS. INVESTIDURA Y MOCIÓN DE CENSURA. EL ARBITRISMO DOCTRINAL.

IV. CONCLUSIONES. BIBLIOGRAFÍA. 
El presente trabajo tiene objetivos muy modestos. Ni por su extensión ni por su profundidad intenta sentar premisas o conclusiones especialmente novedosas u originales. Menos aún, inapelables. Antes bien, trata de llamar la atención sobre determinados elementos de nuestro ordenamiento constitucional: el sistema electoral, el régimen de investidura del presidente del Gobierno y la moción de censura. Y lo hace desde la perspectiva que ofrecen nuestra Constitución y su sistema político más de cuarenta años después de la aprobación de aquella.

Lo que puedan tener de (relativamente) novedosas estas líneas no estriba en las materias sobre las que se centra. Tampoco en la normativa que las regula o la jurisprudencia recaída sobre ellas. De lo que se trata es de reflexionar con qué prodigiosa frecuencia el mero transcurso del tiempo desmonta con eficaz contundencia interpretaciones jurídicas que se han convertido en tendencias dominantes. En ellas, con una convicción digna de mejor causa, se extraen conclusiones a las que una visión retrospectiva les resulta bastante inmisericorde. Lo que en algún momento pudo ser cierto, hoy no lo es en absoluto. Lo llamativo del caso es que esta invalidez de las afirmaciones y predicciones doctrinales no deriva de ninguna palabra nueva emitida por el legislador, al que, como sabemos, Von Kirchman atribuía la caducidad inmediata de bibliotecas enteras. En las materias de las que me ocuparé no ha habido cambios normativos, al menos no de carácter esencial. La obsolescencia de las tesis doctrinales que expondré proviene, más bien, de que sus autores no las condicionaban al hic et nunc con el que la ciencia rigurosa debe actuar, sino que proclamaban su carácter general y validez incondicionada con una alegría desmedida y una confianza excesiva.

Mediante el uso de una técnica "impresionista" de brochazos sobre aspectos concretos, se pretende también llegar a la conclusión de que nuestra vigente Constitución y alguno de sus derivados más inmediatos (en este caso, el sistema electoral) son textos y regímenes mucho más abiertos y dúctiles de lo que buena parte de sus intérpretes han venido sosteniendo. Pertenezco al grupo de quienes muestran escepticismo hacia tantas propuestas de reformas tan bienintencionadas como inútiles y contraproducentes. Sin creer en la sacrosanta inmutabilidad del texto constitucional, pienso que la Constitución española de 1978 ha ido incorporando con fluidez a su tejido social a nuevas generaciones y ve desaparecer inexorablemente a otras, especialmente a aquellas que estuvieron en la génesis social y política de su aprobación.

Para que no haya malentendidos, señalo desde ya que no es mi intención efectuar un indebido ejercicio de "reparto de culpas" a quienes han mantenido posiciones que se analizarán y criticarán intelectualmente en este trabajo. Creo firmemente que en nuestro país sobramos muchos profetas del pasado. Pero también es cierto que nuestra doctrina no se caracteriza, al menos en el ámbito del derecho -que es el que conozco-, por realizar con la necesaria frecuencia una revisión de sus propias tesis. Afortunadamente, la ciencia opera con otros parámetros y transita la senda del error y el acierto. 
En cambio, buena parte de los juristas desconfían de las propias normas, de su adaptabilidad y flexibilidad. Los operadores del mundo jurídico (con especial referencia al gremio académico -si se me permite, y con todo el respeto y cariño debidos-) tienden a olvidar con demasiada frecuencia y facilidad el carácter de la materia sobre la que trabajan: el derecho. Y, lo que es más contraproducente aún, el medio al que se aplica: la sociedad.

Me interesa detenerme en este último aspecto. Cuando inicié mis estudios de Derecho en la universidad preconstitucional española de mediados de los setenta del pasado siglo, tuve la fortuna inmensa de cruzarme con algunos maestros a los que nunca agradeceré suficientemente sus enseñanzas. En el caso del profesor Laporta San Miguel, fuera de todo lo que era habitual en las apolilladas cátedras de Derecho Natural, nos hizo leer relevantes textos del gran científico Mario Bunge. Desde aquel momento me quedó bastante claro que en las llamadas "ciencias sociales", entre las que el derecho ocupa relevante lugar, el adjetivo "social" suele predominar con abrumadora frecuencia sobre el sustantivo "ciencia". Los recientes acontecimientos vinculados a la expansión de la covid-19 en todo el mundo me han recordado, una vez más, cómo la ciencia (la auténtica) avanza entre dudas, autocuestionamientos y ejercicios infinitos de prueba y error. No hay certeza alguna hasta que se puede dar por certificado o avalado de manera irrefutable lo que se investiga. En el ámbito del derecho -también y muy especialmente en la política, todo hay que decirlo- es mucho más habitual encontrarse con afirmaciones pretendidamente inobjetables y auténticas, cuyos autores las emiten con la naturalidad de quien no piensa ni por un momento que en el futuro las cosas pueden cambiar. Es muy humano convencernos firmemente de nuestras posiciones. Pero es todavía más humano errar.

Los temas de los que me ocuparé en este artículo tienen, entre otras, una característica común. En todos ellos se ha utilizado con excesiva frecuencia la injustificada fe que muchos juristas depositan en algo que personalmente siempre pongo en duda. A saber, que la existencia de un determinado tipo de normas (en este caso, la Constitución y la Ley Electoral) predetermina y condiciona de manera casi irremediable la realidad social y política sobre la que se aplican. Es indudablemente cierto que el ordenamiento jurídico influye y condiciona las relaciones en aquellos aspectos sobre los que versa, con el añadido del empleo legítimo de la fuerza del que carecen las reglas éticas, religiosas o del trato social. Esto constituye, en última instancia, su razón de ser. Pero, como antes apunté y luego tendré oportunidad de intentar demostrar con datos evidentes, el sistema normativo ofrece múltiples posibilidades de ser aplicado a realidades cambiantes y a sociedades en permanente evolución ${ }^{1}$.

1 ¿Acaso alguien en su sano juicio puede afirmar que era consciente desde el principio de que el artículo 32.1 CE, que determina que "El hombre y la mujer tienen derecho a contraer matrimonio con plena igualdad jurídica", vigente desde 1978, iba a desembocar en la aprobación de la Ley 13/2005, cuya plena constitucionalidad ratificó la STC 198/2012? 
Insisto en que esto es perfectamente posible, al margen de reformas urgentes y formales de las normas a las que tanta afición muestran políticos de cualquier coloratura, con especial mención a los populistas de toda laya. Por todo ello, este trabajo versa sobre algunos ejemplos de lo que, dadas sus normas reguladoras, nunca podía pasar. Y que, por supuesto, ocurrió.

\section{LA IMPREVISTA \\ FLEXIBILIDAD DEL SISTEMA ELECTORAL ESPAÑOL}

1. En ocasiones conviene recordar las obviedades. Una de ellas es que el sistema electoral es un elemento fundamental de cualquier régimen democrático. Afecta de manera esencial al funcionamiento del ordenamiento constitucional y político en su conjunto, e influye de manera determinante en el modo en que la sociedad y los propios operadores políticos conciben la realidad. Además, condiciona directamente el modo de comportarse tanto de los ciudadanos como de la impropiamente denominada "clase política".

En un esclarecedor artículo en el que pasa repaso al estado de la doctrina, Nohlen señala que:

Las controversias sobre sistemas electorales tienen como objeto los efectos que ejercen sobre los sistemas de partidos políticos. Esta definición, por su parte, ya es controvertida. Las controversias científicas al respecto se dirigen a las relaciones entre sistemas electorales y sistemas de partidos en general, suponiendo una relación de dependencia mutua entre ellos. En el centro se sitúa la cuestión de la causalidad y cómo se la puede abordar y declarar. En contraste, las controversias políticas tratan en primer lugar la opción entre uno u otro sistema electoral. Las respectivas fundamentaciones se deducen de diferentes consideraciones entre las que las científicas figuran generalmente como secundarias ${ }^{2}$.

Aceptando que la controversia política deja muy en segundo lugar las coincidencias científicas, resulta mucho más difícil de admitir que las de índole "científica" estén exentas de contaminación política. Ya he señalado anteriormente mi sano escepticismo sobre la cientificidad "social". Señalo ahora, y pondré algún ejemplo después, cómo los investigadores y profesores no son inmunes a sus propias convicciones sobre las bondades o perversiones de un sistema electoral. 
2. Una característica común a los sistemas electorales es que, como señaló Lijphart, tienden a ser muy estables y resistentes al cambio ${ }^{3}$. Esta realidad no es casual. Tanto en su vertiente normativa como en el resto de sus manifestaciones, el núcleo duro de los sistemas electorales forma parte fundamental de la cultura política comúnmente asumida por una comunidad políticamente estructurada. El ciudadano medio puede, con relativa seguridad, describir los elementos esenciales de su sistema electoral: desde dónde ha de votar, cuál es su circunscripción, cómo ha de votar, qué es lo que está votando, etcétera. ¿Cómo explicar, si no, que la inmensa mayoría de los norteamericanos - y buena parte de los que no lo somos- sepan que las elecciones presidenciales se celebran el primer martes después del primer lunes de noviembre cada cuatro años? ¿Cómo se admitiría tan fácilmente que un candidato sea elegido presidente con tres millones menos de votos populares que su contrincante?

Solo la aceptación de que el sistema electoral tiene una estabilidad a prueba de bombas y de que las reglas "son las que son" permite entender escenarios que, de otro modo, serían absurdos o grotescos. Aún más: allí donde se han alterado con frecuencia en un corto espacio de tiempo las reglas electorales ${ }^{4}$ ha quedado muy claro, desde el primer momento, el carácter nada funcional o altruista de los cambios; unos cambios que, por cierto, acabaron -por aquello de la justicia poética-, volviéndose contra sus autores. Una muestra, otra más, de cómo reformas urgentes y ad hoc terminan siendo disfuncionales y, con frecuencia, devuelven a la casilla de salida.

La estabilidad no es un bien en sí mismo necesariamente. Pero me parece útil prevenir contra el experimentalismo antes de introducir cambios o reformas en lo que la ciudadanía entiende y comprende, por más que en ocasiones despotrique contra ello.

3. Lo anterior no empece para reconocer que la fijación de un determinado sistema electoral busca objetivos concretos y determinados. Los sistemas no son neutros, como tampoco lo son sus autores. Estos aún menos. Existen estudios y pronósticos muy ajustados sobre los resultados que se derivan del empleo de unas u otras reglas. Por ello, hay que presumir, sin posibilidad de error alguno, que nadie es benéfico, neutral o desinteresado cuando se trata de articular un sistema electoral. De ahí se deriva, a mi entender, otro desiderátum: la aprobación del sistema electoral de un país debe contar con un apoyo político y social muy amplio. Más extenso, si cabe, que la deseable convergencia que debe aplicarse a la inmensa mayoría de cuestiones. Allí donde los sistemas electorales oscilan y cambian en función de mayorías transitorias, accidentales o coyunturales, la sospecha se torna tan legítima como generalmente acertada.

3 (Nohlen, 2013: 29).

4 El ejemplo de las reformas electorales impulsadas por el presidente Mitterrand en Francia en 1985, basadas en exclusivos intereses personales o partidarios, es un caso tan paradigmático como el famoso porcellum de Berlusconi en 2005 con su prima de mayoría. 
A la estabilidad de la normativa electoral contribuye sobremanera la proclividad a no cambiarla por parte de quienes han sido capaces de ganar unos comicios celebrados bajo su amparo. Lógico.

4. El sistema electoral español tiene tres hitos básicos:

- El Real Decreto-ley 20/1977, de 18 de marzo, sobre Normas Electorales.

- La Constitución española de 1978, señaladamente sus artículos 68 y 69.

- La Ley Orgánica 5/1985, de 19 de junio, del Régimen Electoral General (en adelante, LOREG).

A lo cual hay que sumarle, lógicamente, las diferentes regulaciones de ámbito autonómico contenidas en sus leyes reguladoras, con la llamativa excepción de Cataluña.

Si bien es cierto que la LOREG ha tenido múltiples reformas ${ }^{5}$ es indiscutible que la continuidad y la estabilidad constituyen los rasgos esenciales de la normativa electoral española.

El Real Decreto-ley de $1977^{6}$ marca unas líneas de las que poco se despegarán las normas que vienen a completarlo o sustituirlo. Si el éxito de un sistema electoral puede medirse por la consecución de los resultados políticos que sus autores deseaban alcanzar, puede afirmarse, sin ningún género de duda, que el modelo resultó triunfal. Tanto que, dejando de lado algunos aspectos puramente transicionales -como los senadores de designación real-, los artículos 68 y 69 de la Constitución consagran y refuerzan, con el valor propio de su rango, las características esenciales del sistema. No le correspondía a la Constitución desarrollar in extenso un concreto modelo de sistema electoral y no lo hizo, traspasando a la Ley Electoral su regulación. Fijó, eso sí, los elementos nucleares: proporcionalidad para el Congreso, sistema mixto y mayoritario para el Senado, etcétera. Al no apartarse de lo que era una norma preconstitucional, el modelo quedó legitimado con la ratificación de la Constitución.

Siete años después, la LOREG vendría a perfeccionar, extender y consolidar el régimen electoral pero sin alterar ninguno de sus aspectos estructurales ${ }^{7}$. Y así, veintidós reformas después, hasta el día de hoy.

No es el objetivo de este texto -no hace falta explicar por qué- analizar en profundidad las virtudes y los defectos de nuestro sistema electoral. Sí quiero, por el contrario, afirmar que las críticas políticas y científicas que "inevitablemente" iban asociadas al sistema electoral español han quedado desmentidas por la realidad, al menos en una parte muy significativa. Con datos y números.

5 Hasta veintidós. Muchas de ellas son manifiestamente innecesarias o mejorables, cuando no contraproducentes. Eso sin contar con la doctrina del Tribunal Constitucional recaída sobre la ley tanto a través de recursos de inconstitucionalidad o amparo como mediante el planteamiento de cuestiones de inconstitucionalidad.

6 Cuya génesis se encuentra sintéticamente expuesta en Torres del Moral, (2009: 59 y siguientes).

7 Llama la atención que, después de un rodaje de ocho años de los efectos del sistema creado en 1977, el texto final de la LOREG sólo tuviera dos abstenciones y dos votos en blanco. Demostración palpable, por cierto, de lo anteriormente afirmado sobre la bondad del consenso en la aprobación de las leyes electorales. Eso sí, el listón quedó muy alto. 
5. La doctrina que se ha ocupado de analizar el sistema electoral español ha sido, en términos generales, coincidente en señalar que sus resultados políticos, en especial el sistema de partidos, eran consecuencia ineluctable de los parámetros de aquel. En este pensamiento les han acompañado siempre aquellos partidos y formaciones que se creían claramente perjudicados por el sistema vigente ${ }^{8}$.

Las tesis principales estriban en que un sistema con numerosas circunscripciones de escaso tamaño en cuanto al número de escaños a repartir, unido a un sistema de listas cerradas y bloqueadas y la aplicación de la regla D'Hondt abocan inexorablemente a un bipartidismo que, en el mejor de los casos, podía ser imperfecto. También ha sido una letanía compartida afirmar que el sistema empuja decisivamente al elector hacia el llamado "voto útil", inclinándole hacia una de las fuerzas mayoritarias, bien sea en la modalidad del voto positivo o en la vertiente del sufragio negativo contra aquel partido cuya llegada al Gobierno no se desea.

Dentro de la ingente producción doctrinal que podría traerse a colación, y que desbordaría de por sí un trabajo de estas dimensiones, me quedo con el interesante artículo que el profesor Torres del Moral publicó el año 2009. En un año tan cercano al actual en términos de secuencia histórica, el autor, tras analizar con precisión y rigor la génesis del sistema electoral y bajo el expresivo rótulo de "El inencontrable pluripartidismo del sistema político nacional", concluye que:

Si una tendencia se observa en el elector español es la de ir concentrando sus votos en unos pocos partidos, justo los que puedan formar Gobierno o puedan ayudar a ello, o, en fin, puedan oponerse con eficacia y perspectivas de alternancia política. Del resto se encarga el propio sistema con la prima electoral que otorga a unos y la penalización que impone a otros ${ }^{9}$.

Es ventajista y, por tanto, poco justo aplicar sin más el sesgo retrospectivo a una afirmación efectuada al principio de la gran recesión, que comienza en 2008. Que en ese momento se apreciara esa tendencia es una opinión perfectamente asumible. Lo que desde luego no era cierto - a mi entender, ni entonces ni ahora- es que la concentración sea una consecuencia del sistema. El propio autor admite que la dicotomía entre el buen pluripartidismo (moderado) y el mal bipartidismo (artificial) es una tesis interesada. Eso no le impide insistir en la atribución de estos efectos al sistema electoral ${ }^{10}$.

A mediados de 2020, cuando se escriben estas líneas, el núcleo estructural de la LOREG permanece intacto en lo que se refiere a los parámetros esenciales del sistema

8 Señaladamente el Partido Comunista y luego Izquierda Unida. Pero, con diferentes grados de intensidad, puede afirmarse lo mismo del CDS, UPyD y tantos y tantos cadáveres más o menos exquisitos de la política nacional.

9 (Torres del Moral, 2009:73). Tesis reiterada explícitamente en la página 78 del mismo trabajo donde añade al respecto que "Y, acaso de una manera sorprendente, dicha tendencia se acentúa en las elecciones autonómicas". 
electoral. Y, sin embargo, nadie que observe con atención lo que viene sucediendo desde 2015 puede sensatamente afirmar que nada ha cambiado. Menos aún que el bipartidismo se ha reforzado.

Desde el 15 de junio de 1977 se han celebrado en España quince elecciones generales para el Congreso de los Diputados y el Senado. Al amparo de diversas normas reguladoras, pero, en lo sustancial, bajo idéntico sistema electoral. El número de fuerzas políticas representadas en el Congreso de los Diputados ${ }^{11}$ ha variado desde las 12 de los primeros comicios de 1977 hasta las 21 de las últimas elecciones de noviembre de 2019.

En cuanto a la suma del porcentaje de votos válidos obtenidos por los dos partidos más votados en las elecciones generales, el profesor Sánchez Muñoz señala cómo ha variado hasta las elecciones de 2011 en una horquilla que va desde el 63,76\% de los votos de junio de 1977 hasta el 83,81 \% (máximo histórico) en $2008^{12}$. Por mi parte añado que esa suma alcanza un mínimo histórico del 45,36 \% en las elecciones de abril de 2019, para repuntar levemente hasta el 48,22 \% en las elecciones de noviembre de ese mismo año. Todo ello precedido del 50,71 \% en diciembre de 2015 y del 55,64 \% de abril de 2016.

Afirma Sánchez Muñoz que:

Lo cierto es que en nuestro país el sistema sí ha tenido una influencia muy decisiva, hasta el punto de que estamos, como señala Presno Linera, ante un "caso paradigmático en el Derecho comparado" de influencia del sistema electoral sobre el sistema de partidos ${ }^{13}$.

Si el sistema y las reglas son las mismas y los resultados, a partir de diciembre de 2015, a través de cuatro elecciones extraordinariamente consecutivas en el corto espacio de menos de cuatro años, son tan distintos a los anteriores, ¿cuál es la pregunta? Parece que sí, que debe ser la que se estará, sin duda, formulando cualquier lector mínimamente atento: ¿y si esa predeterminación no era tan exacta y esa influencia no era tan "paradigmática", por emplear la terminología del profesor Presno? ¿Es oportuno cuestionarse la pretendida causalidad? No deja de resultar llamativo que, cuando los hechos son manifiestos y el cambio de la realidad tan evidente, sigue habiendo una feroz resistencia a cambiar teorías, análisis y enfoques, por no decir apriorismos ${ }^{14}$.

11 Dejo de lado el caso del Senado, cuyo sistema electoral mayoritario es mucho más proclive, lógicamente, al bipartidismo.

12 (Sánchez Muñoz, 2017: 240). La cifra altísima de 2008 quizá explique las rotundas afirmaciones de Torres del Moral hechas al calor de este resultado.

13 (Sánchez Muñoz, 2017: 244). La referencia al trabajo de M. A. Presno Linera "Régimen electoral ("maquiauélico”) y sistema de partidos (con sesgo mayoritario)" en Revista Española de Derecho Constitucional 104, 2015, págs. 13-48.

14 El título del trabajo del profesor Sánchez Muñoz es muy revelador al respecto. Todavía en 2018 se puede leer en la web de la universidad de Granada que "matemáticos diseñan un sistema electoral más equilibrado que acabaría con los problemas de representatividad en el Congreso de los Diputados" (https://canal.ugr.es/noticia/matematicos-sistema-electoral-equilibrado/) donde se da cuenta de los resultados de la investigación dirigida por el catedrático D. Victoriano Ramírez González. ¿De verdad que hay un déficit de representatividad en una Cámara con veintiuna fuerzas políticas o partidos representados? 
Sucede que, incluso cuando se es capaz de detectar la realidad, nos resistimos a aceptarla tal cual es. Porque no nos gusta o porque ver cómo se caen a pedazos tópicos tan queridos es cruel con nuestra propia historia y recuerdos. De ahí que, a mi entender, no se hayan sacado todavía las debidas conclusiones del cambio de paradigma. Un buen ejemplo lo tenemos en el trabajo de Sánchez Muñoz. A su juicio, la ruptura del bipartidismo en las elecciones de 2015 y 2016, al menos en su versión más extrema, se debe en primer lugar a:

la distribución del voto entre los demás partidos. En 1977, la tercera y cuarta fuerza políticas (PCE y AP) obtuvieron solo 1,7 y 1,5 millones de votos respectivamente, lo que dificultó su acceso a escaños en gran parte de las circunscripciones. En 2016, en cambio, la tercera fuerza (Unidos Podemos y sus confluencias) ha obtenido 5,1 millones de votos y la cuarta fuerza (Ciudadanos) ha logrado 3,1 millones, lo que ha permitido que estos partidos hayan podido acceder a la representación en circunscripciones de menor magnitud ${ }^{15}$.

Siendo totalmente cierto lo afirmado, sorprende la ausencia de una constatación previa y bastante más elemental. En 1977 la suma de la tercera y la cuarta fuerza representaba 3,2 millones de votos y un 17,54 \% del total de los mismos. Por el contrario, en junio de 2016 sumaban 6,3 millones de votos, que significaron el 26,48 del total. Nueve puntos más y el doble de votos, ni más ni menos. Pues bien, suele suceder en los sistemas proporcionales -y el nuestro lo es, quiérase o no-, que si se obtienen más votos se suelen obtener más escaños; incluso, que si se obtienen bastantes más votos es probable que se obtengan bastantes más escaños, aun cuando la proporcionalidad no sea matemáticamente exacta, lo que no suele ocurrir en ningún sistema por muy proporcional que sea.

Dicho de otra manera: no estamos ante un problema -o, al menos, no solo o no principalmente- de la "distribución" de los escaños entre la tercera o cuarta fuerza, sino ante algo más primario: fuerzas políticas distintas de las dos dominantes han obtenido más votos, muchos más, que en anteriores ocasiones. Salvo que por "distribución” entendamos que las dos fuerzas que en el pasado obtenían muchísimos más sufragios hoy logran una cantidad significativamente menor. A pesar de las apariencias de las noches electorales, los comicios operan sobre un $100 \%$ en el que unos ganan lo que otros pierden.

6. Sorprende especialmente que buena parte de la doctrina haya pasado por alto el hecho de que la mayoría de los sistemas políticos autonómicos dejaron de ser, hace tiempo, bipartidistas. De hecho, en algunas comunidades tan significativas como País Vasco o Cataluña es dudoso que alguna vez lo hayan sido. 
Pero más extraño todavía es que, en general, no se haya percibido que el gran motor de ese cambio en el sistema de partidos fue la convulsión económica y social originada por la gran recesión de 2008. Sin entrar en detalles que nos llevarían muy lejos de los límites de estas líneas, la articulación de las sociedades se ha trastocado enormemente y fenómenos como el precariado, la exclusión social, la globalización o su repliegue, el empobrecimiento general, etcétera, han sido un caldo de cultivo de la desafección social. Esta se ha dirigido de un modo muy especial hacia las fuerzas que representaban el statu quo anterior y ha favorecido, consiguientemente, la aparición de nuevos partidos o movimientos respaldados por amplios segmentos de la población.

Es evidente que este no es un fenómeno específicamente español. En países tan significativos como Francia e Italia gobiernan partidos o formaciones cuya mera existencia era una quimera hace una década. Tampoco allí el sistema electoral, concebido y desarrollado por fuerzas políticas preexistentes y más o menos tradicionales, ha impedido el ascenso fulgurante de nuevos partidos o movimientos. En otras partes del mundo, donde los ropajes formales mantienen las apariencias, tampoco la realidad se asemeja a lo anterior. Salvo que aceptemos que el Partido Republicano de Trump es el mismo o lo mismo que el de Gerald Ford o el de Bush sénior, lo que parece mucho admitir.

Pues bien, frente a esta realidad social tan alterada y líquida -por emplear una metáfora que ha hecho fortuna-, todavía seguimos operando con clichés periclitados y desmentidos por la realidad. Pondré dos ejemplos arquetípicos que han funcionado en nuestra doctrina como mantras incontestables.

El primero se expresa en la regla de que la coincidencia en nuestro sistema electoral de muchas pequeñas circunscripciones con un número muy limitados de escaños a repartir impide radicalmente la proporcionalidad en esa circunscripción y en el sistema en su conjunto. Este es un pensamiento tan generalizado que convierte en innecesaria cita alguna. Vayamos a las últimas elecciones celebradas en noviembre de 2019. Centrémonos en una provincia tan reducida y con tan pocos escaños a repartir como Teruel. Tres exactamente. El primer escaño correspondió a la agrupación de electores Teruel Existe, con 19.761 votos y un porcentaje del 26,66 \%. El segundo, al PSOE, con 18.934 votos y un $25,54 \%$. El tercero y último, al PP, con 17.520 y un $23,63 \%{ }^{16}$. Es decir, tres fuerzas se reparten de manera muy equilibrada un 75,83 \% del electorado de la provincia. ¿Qué sesgo mayoritario o distorsionador de la proporcionalidad ha introducido el sistema? Evidentemente ninguno. Si los votos se reparten proporcionalmente, el sistema lo refleja con bastante fidelidad. Y, desde luego, sin alterar la realidad política expresada por el electorado. Para ser una provincia modelo en donde era imposible la proporcionalidad, no está nada mal. 
El segundo de los mantras habituales de los que me ocuparé es aquel que consiste en afirmar que la obligación de listas cerradas y bloqueadas desincentiva la participación y minusvalora el papel de la ciudadanía. Siempre he considerado errónea esta premisa. De una parte, ese modelo de lista abierta dentro de los partidos originó en algunos países (el caso de Italia fue paradigmático) fenómenos indeseables de financiación irregular o directamente delictiva en favor de determinados candidatos o en contra de otros. Por otra, la realidad del voto en nuestro Senado, donde el elector puede elegir libremente entre candidatos de diversos partidos, muestra de manera reiterada y contumaz lo irrelevante de esta posibilidad tanto en términos estadísticos como políticos. Un ejemplo más de que la ciudadanía tiene "interiorizado" un determinado sistema electoral muy rodado y experimentado. En el nuestro, al menos a nivel nacional -otra cosa son las elecciones locales-, se vota fundamentalmente a partidos políticos y no a candidatos. Solo el perfil del líder nacional puede influir en esta cuestión. Y, aun así, tengo mis dudas. Candidatos de excelente factura se han estrellado en las urnas y otros a los que se les ven claramente las costuras han ascendido al estrellato. No seré tan maleducado como para señalar.

7. A modo de conclusión, me permitiré unas breves reflexiones. La primera es que conviene huir del arbitrismo como de la covid-19. Cuando se nos intenta vender política o doctrinalmente un concreto sistema electoral, la desconfianza me parece una actitud muy aconsejable. No porque el sistema vigente sea inmejorable, que no lo es, sino porque las pretendidas mejoras rara vez son inocuas y con frecuencia la realidad desmiente su viabilidad.

La segunda es que, por lo que he señalado anteriormente, el sistema electoral español ha demostrado en los últimos años -frente a afirmaciones de índole contraria de políticos y teóricos-, que es mucho más flexible de lo que afirmaba; que no predetermina, ni mucho menos, unos resultados concretos, y que, sin duda alguna, es mucho más proporcional de lo que se afirmaba. En resumen, que no se ha encontrado en el sistema electoral obstáculo o valladar que haya impedido que los cambios sociales se reflejen en la atribución de escaños. Claro que lo que parece desproporcionado es que cuando la realidad social era muy mayoritariamente bipartidista el sistema la convirtiera en una ficticia pluralidad ${ }^{17}$.

Gestionemos, pues, la realidad de una manera correcta. No echemos la culpa al empedrado. Y, si consideramos que estos son tiempos de crisis, acordémonos de la máxima ignaciana. Si nos empeñamos en reformar el sistema, por lo menos no nos centremos en reformas innecesarias. No me parece mucho pedir.

17 Un reconocimiento de esta realidad frente a la tesis "repetida una y mil veces" en Blanco Valdés (2017: 84). 


\section{LA TRASLACIÓN DEL “PROBLEMA” \\ A OTROS ÁMBITOS. INVESTIDURA Y MOCIÓN DE CENSURA. EL ARBITRISMO DOCTRINAL}

1. Reconocido el cambio de sistema de partidos en España ${ }^{18}$, se pasa a apuntar lo profundamente inconveniente que sería abordar ahora la propuesta reforma del sistema electoral ${ }^{19}$.

Lo que sucede es que el nuevo sistema pluripartidista, lejos de admitirse como una realidad que tiene unas causas contrastables y profundas, se plantea como un "problema"20.

Como señala López Rubio ${ }^{21}, 2016$ fue el año que inició las grandes novedades en estas cuestiones. A partir de entonces no ha resultado fácil formar gobiernos en España, producto, sin duda, del nuevo sistema de partidos consolidado en hasta cuatro elecciones casi consecutivas. La primera pregunta es si es cierto que estamos ante un problema de ingobernabilidad. La segunda es si, aceptada una respuesta positiva, son las normas vigentes las que han causado el problema. En el caso del sistema electoral, nos ha llevado casi cuarenta años percatarnos de que la ecuación que daba como resultado inexcusable el bipartidismo era falsa. Con un poco de atención tal vez podamos acortar plazos en esta ocasión.

2. Como era previsible, la doctrina se ha volcado en estudiar aquellas instituciones directamente relacionadas con el nacimiento y cese de los gobiernos. De repente, florecen los trabajos sobre la investidura y la moción de censura. Sucedió igual no hace mucho con el artículo 155 CE y -reciente y desgraciadamente-, con el artículo 116.2 CE y el estado de alarma. Lo de Santa Bárbara y los truenos es un clásico doctrinal. Lo curioso es que hasta hace no mucho era común la opinión de que:

El artículo 99 es una de las disposiciones de la Constitución que suele aparecer en los repertorios anotados huérfano de referencias legislativas o jurisprudenciales. Y ello, no por descuido de los autores de tales repertorios, sino porque la letra del artículo se nos aparece en términos tan diáfanos que es difícil concebir conflictos a propósito de su aplicación que no sean de aquel tipo que solemos calificar desdeñosamente como "hipótesis de laboratorio"22.

18 (Blanco Valdés, 2017: 88) "que, insisto, la legislación no ha impedido en cuanto se ha alterado también la correlación de fuerzas entre los principales competidores del sistema".

19 (Blanco Valdés, 2017: 88).

20 El cinematográfico título del trabajo del profesor Blanco Valdés lo refleja perfectamente: “El año que vivimos peligrosamente: del bipartidismo perfecto a la perfecta ingobernabilidad".

21 "2016 se convirtió así en el año en que acontecieron situaciones nunca antes vistas en nuestro sistema político-constitucional. Por primera vez un líder político declinaba el ofrecimiento del Rey de ser candidato a la Presidencia del Gobierno. Por primera vez el Rey propuso como candidato al líder de una formación que no había ganado las elecciones. Por primera vez un candidato no obtuvo la confianza del Congreso de los Diputados en una sesión de investidura. Y por primera vez se procedió a la disolución automática de las Cortes Generales ante la imposibilidad de formar un gobierno tras dos meses desde la primera votación" (López Rubio, 2017: 160). Y lo que quedaba, añado yo.

22 (Revenga Sánchez, 2004: 506). 
Y, en lo tocante a la moción de censura, se consideraba una "vía muerta parlamentaria, dadas las dificultades constitucionalmente impuestas para su sustanciación"²3. Hoy se analizan con lupa microscópica los artículos 99 y 113 de la Constitución. Y a muchos autores lo que ven no les gusta. De ahí a proponer medidas reformadoras que palíen o eliminen los problemas que creen detectar hay un corto paso al que es difícil resistirse. De esta manera se vuelve a entrar, sin transición, en el arbitrismo de ofrecer soluciones de reformas ad hoc que corrijan los supuestos errores y disfunciones detectados en el texto constitucional. Así, piensan, se sanará el sistema político y se dará paso otra vez a la añorada gobernabilidad.

Analizaré varias de las propuestas para recapacitar sobre su bondad y operatividad, que adelanto que considero muy escasa.

3. La investidura ${ }^{24}$ es un modelo novedoso en nuestro constitucionalismo que no surge de la nada. Frente al doctrinarismo canovista de amplio uso y abuso por parte de Alfonso XIll y a la mala experiencia de la gestión que en esta materia llevó a cabo Alcalá Zamora en la Segunda República, el constituyente de 1978 busca un modelo plenamente acorde con el enunciado de "Monarquía parlamentaria" del artículo 1.3 CE ${ }^{25}$. De esta manera, se atribuyen facultades al rey, aunque bastante tasadas como luego se verá, y se sitúa en la responsabilidad de las fuerzas políticas la tarea de llegar a acuerdos que puedan plasmarse en el Congreso de los Diputados, para lo cual se exige una mayoría absoluta en la primera votación y una simple en la segunda.

Se huye, por consiguiente, de un sistema de confianza implícita para el nacimiento del Gobierno. Lo cual le dota de una gran legitimidad ab initio. Pero, claro está, esto va en contra de los apresuramientos y urgencias que aquejan a muchos de nuestros autores.

La realidad de casi cuarenta años de praxis constitucional es que si, al igual que sucedía con el sistema electoral, el objetivo era conseguir estabilidad y gobernabilidad, el modelo ha sido un paradigma de éxito. El bipartidismo más o menos perfecto funcionó como un reloj en lo que se refiere a la investidura, tal y como acredita la cita anterior del profesor Revenga. Conviene, no obstante, recordar que, si bien el sistema era muy funcional, en ocasiones obtener las mayorías requeridas no era tan simple y obligaba a pactos no siempre sencillos u obvios. Así, por ejemplo, refiriéndose al apoyo prestado por Convergencia i Unió, PNV o ERC a los Gobiernos de Rodríguez

23 (Bar Cendón, 1998: 290).

24 Un buen resumen de esta institución puede encontrarse en el trabajo de Bar Cendón antes citado.

25 (Revenga Sánchez, 2017: 107). 
Zapatero, Blanco Valdés considera que lo hicieron como "partidos extractivos"26. A mi entender, esta terminología, de clara impronta minera -parece que no aplicable a algunos gobiernos de González o a Aznar I-, se asemeja bastante a lo que en el mejor de los sentidos se denomina "hacer política". Ni toda la política se hace desde dentro del Gobierno ni parece imprescindible exigir a partidos de ámbito no nacional su entrada en el Gobierno de España. Cuando los senadores de Michigan pactan su apoyo a proyectos de ámbito nacional en el Capitolio a cambio de ayudas para la industria automovilística de Detroit, a nadie se le ocurre que estén "extrayendo" nada, sino que se les felicita por sus logros para la circunscripción. Incluso es posible que sea más favorable para su reelección.

Aprovecho para recordar que, como señala Torres del Moral, la supuesta hiperrepresentación nacionalista en el Congreso es otro más de los mitos con los que se ha denostado nuestro sistema electora ${ }^{27}$. A modo de ejemplo, es al menos discutible si fue mejor para España la legislatura Aznar I o la II. Pero, después de la legislatura "extractiva”, el Partido Popular pasó de 156 escaños a 183. En la elección subsiguiente a la de mayoría absoluta bajó de 183 a 148 y perdió el Gobierno. El electorado sí tuvo claro cuál le gustó más. Más adelante tendré oportunidad de recordar cómo acabaron algunas experiencias de "nueva política" cuyo objetivo inicial era acabar con esas prácticas "extractivas".

Las opiniones generalmente muy favorables al diseño constitucional de la investidura tienen la gran ventaja de haber sido emitidas en época no sospechosa y, por tanto, estar basadas en el análisis jurídico y no tanto en los desajustes políticos posteriores. Ha bastado con que el electorado haya mutado o dispersado sus preferencias, que el sistema de partidos se haya alterado significativamente, para que buena parte de la doctrina crea percibir que el empedrado no está bien alineado. De ahí se pasa al veredicto: la norma es culpable.

Esta vez la crítica doctrinal -muy seguida en los medios por los tertulianos habituales, aunque en ocasiones coinciden las dos cualificaciones- alcanzó tanto predicamento que fue asumida por significativos representantes políticos. En el debate de investidura de 22 de julio de 2019, el candidato Pedro Sánchez, ganador de las elecciones de abril, ofrece como primera medida una oferta de "pacto de Estado" que consiste -ya

\footnotetext{
26 "es decir, como auténticos grupos de presión, que, sin entrar jamás en el Gobierno y sin asumir, por tanto, la responsabilidad derivada de su gestión y decisiones, le ofrecían su apoyo parlamentario al ejecutivo de que se tratase en cada caso a cambio de obtener contrapartidas políticas (más poder y competencias) y económicas (inversiones y mejor financiación) del Gobierno del Estado a fauor de sus respectivos territorios autonómicos. Como no podía ser por menos, ello acabaría por constituir un gran problema en el desarrollo de nuestro proceso de descentralización, pero también por influir en el modelo parlamentario español de un modo decisivo" (Blanco Valdés, 2017: 70).

27 (Torres del Moral, 2009: 80).
} 
es casualidad-, en la reforma del artículo 99 de la Constitución ${ }^{28}$. La necesidad o la urgencia de esta reforma, fundamentada en el mantra de la gobernabilidad ${ }^{29}$, no debía de ser tan evidente o apremiante cuando desapareció de los ulteriores programas que el mismo candidato presentó ante el Congreso en las sucesivas ocasiones en que compareció para idéntico trámite.

4. Desde ese momento iniciático que suponen las elecciones de 20 de diciembre de 2015, en las que el primer partido (Partido Popular) se quedó en la magra cifra de 123 escaños y el Partido Socialista en la más exigua aún de 90 , ha sido una constante en la doctrina analizar no solo qué sucedió para que se diera semejante cambio de orientación en el electorado, sino qué fallos o supuestas lagunas concurren en nuestro ordenamiento constitucional para que esto pueda producirse o cómo podemos encauzar lo que el voto popular ha desordenado. Una revisión ordenada del procedimiento de investidura puede ayudar a valorar con precisión los agujeros del sistema, sean estos ficticios o reales.

4.1. El artículo $99.1 \mathrm{CE}$ regula las consultas regias con los representantes designados por los grupos políticos con representación parlamentaria, así como la propuesta de candidato a la Presidencia del Gobierno que hace el rey a través del presidente del Congreso.

No me detendré en el universo de los llamados a consultas porque la propia práctica constitucional ha decantado suficientemente la cuestión. Baste con recalcar que la asistencia a las consultas es libre para los convocados ${ }^{30}$.

Hay quien ha propuesto acelerar este trámite de consultas ${ }^{31}$ con el argumento de que "en ningún sitio se ha dispuesto cuándo deben empezar estas consultas"”2.

28 "A tal fin, señorías, quiero trasladarles una primera oferta de pacto de Estado. Resulta evidente que el artículo 99 de nuestra Constitución, que es el que regula, como bien saben ustedes, el procedimiento de investidura de la Presidencia del Gobierno, debe ser actualizado a la nueva realidad parlamentaria. Los ciudadanos no deben, nunca más, sufrir la amenaza de una repetición electoral; con una votación basta. Al igual que el sistema garantiza la conformación de los Gobiernos municipales el pasado 15 de junio, al igual que se garantiza por parte de muchos estatutos de autonomía la conformación de Gobiernos autonómicos, y al igual que el Gobierno de esta Cámara se garantiza en una sesión plenaria, así debe tener también garantía el Poder Ejecutivo a nivel nacional de poder ser constituido.

Para materializar esta propuesta, este acuerdo, que refuerce sin duda alguna la estabilidad del sistema, les pido que facilitemos entre todos la formación del Gobierno de España y que, posteriormente, abordemos la reforma constitucional del artículo 99 para que nunca más uuelua a ocurrir el bloqueo en nuestro país". D.S.C.D de 22 de julio de 2019, pág. 6. El Partido Socialista tenía en este momento 123 escaños. Es posible que este dato tuviera algo que ver.

29 "Estoy proponiendo, simple y llanamente, que España tenga Gobierno, estoy proponiendo simple y llanamente que España tenga oposición, que España, en definitiva, no quede bloqueada". D.S.C.D. 22 de julio de 2019, pág. 6.

30 Varias fuerzas han declinado acudir a las consultas en las últimas convocatorias, señaladamente ERC y Bildu. locandi causa quiero citar aquí un chiste que circuló ampliamente en las redes sociales. En la foto se veía a Felipe VI hablando por teléfono con quien se suponía que era Juan Carlos I. El hijo le decía al padre "Papá, me dijiste que vendrían cada cuatro años, pero los tengo todos los días metidos en casa".

31 (López Rubio, 2017: 167).

32 A mi juicio, solo la Constitución podría regular este extremo, pero caería en un reglamentismo impropio de su rango. 
Por ello "nada obligaría, pues, a esperar hasta la constitución del Congreso de los Diputados"33. Tampoco comparto las tesis de aquellos que proponen que sea la Mesa del Congreso quien actúe en el nombramiento y no su presidente ${ }^{34}$. Si alguna vez fue verdad -que lo dudo-, que la Mesa era un órgano neutral, remito a las observaciones que formula la mejor conocedora del funcionamiento del Congreso de los Diputados, la profesora y letrada García-Escudero Márquez, sobre las capacidades de obstrucción -la terminología es mía, no suya- de la Mesa a las iniciativas de una oposición transformada en Gobierno ${ }^{35}$.

En su trabajo de 1998, señalaba Bar Cendón la ausencia de un plazo para la realización de las consultas regias y anotaba las ventajas e inconvenientes de esta omisión ${ }^{36}$. A mi juicio, la experiencia histórica demuestra concluyentemente que nunca ha sido el retraso en la celebración de consultas por el rey la causa u origen de perturbaciones constitucionales. Flexibilidad, pues, y presunción de buen criterio ${ }^{37}$.

En relación con la propuesta del rey, sin querer entrar ahora en el margen de discrecionalidad del monarca ${ }^{38}$, los acontecimientos de estos últimos años han planteado dos cuestiones al menos.

La primera es el grado de obligatoriedad respecto a la aceptación del encargo. Parto de la base de que nadie puede ser obligado a ostentar un cargo que no desea, ni tampoco a aceptar encargos en los trámites previos que pudieran llevar hasta ahí. Aunque buena parte del estamento político podría matar -en sentido figurado, claro está- por ser presidente del Gobierno, nadie está compelido a serlo. Por las razones que estime oportunas, el llamado al encargo puede declinar libre y legítimamente el encargo ${ }^{39}$.

33 Esto es totalmente incorrecto por un doble orden de razones. En primer lugar, porque alguien tiene que facilitar al rey la lista de convocables y no parece que esta deba ser la última tarea del presidente saliente sino la primera del entrante. En segundo término, porque las consultas van orientadas a proponer un candidato cuyo refrendo le corresponde al presidente de la nueva legislatura, en ningún caso al anterior. El propio López Rubio, en la tabla que figura en la página 168 de su trabajo, señala que desde 1979 a 2016 la diferencia de días transcurridos entre la fecha de las elecciones y el inicio de las consultas varía entre 22 y 30 días, margen despreciable, a mi juicio, que no justifica la aceleración del trámite.

34 (Bar Cendón, 1998: 272).

35 (García-Escudero Márquez, 2018: 72).

36 (Bar Cendón, 1998: 272).

37 (López Rubio, 2017: 169). En sentido coincidente, Revenga Sánchez: "Dejar a la voluntad del Rey el cuándo del inicio de las consultas en cada supuesto concreto nos parece un factor de indeterminación que encaja perfectamente con su función arbitral y moderadora del funcionamiento regular de las instituciones". (2017: 110).

38 Áluarez Vélez (2016: 7) señala que "... el Rey está sujeto a la obligación constitucional de proponer al candidato que goce de mayores expectativas de obtención de la confianza del Congreso", lo cual tiene bastante de tautológico y muchísimo de concepto jurídico hiperindeterminado.

39 Con todo el respeto, me permito discrepar de la interpretación que Blanco Valdés hace respecto del comunicado de la Casa del Rey de 22 de enero de 2016 (2017) 90. A diferencia de lo sostenido por él, dado que solo hay propuesta jurídicamente relevante cuando se ha culminado el procedimiento, incluido el refrendo del presidente del Congreso, el comunicado no habla en ningún momento de rechazo a la propuesta -acto jurídico muy concreto y tipificado- tal y como recuerda Revenga Sánchez (2017: 110). Actuó de acuerdo con la Constitución el señor Rajoy, sí, pero también SM el Rey. Creo más bien que lo que molestó fue lo que siguió al hecho de declinar el ofrecimiento. 
La segunda, que podría haberse calificado de entelequia no hace tanto, es la posibilidad de que las consultas regias no fructifiquen y, en consecuencia, no haya candidato que proponer. Esto ya ha sucedido en enero de 2016 y en abril del mismo año. Una vez más, llamo la atención sobre la necesidad de interpretar las normas constitucionales de acuerdo con la realidad social. Cuando el artículo 99.1 CE señala que el rey "propondrá un candidato a la Presidencia del Gobierno", no parece estar obligándole velis nolis a estampar un nombre en la propuesta si las circunstancias derivadas de sus consultas y exploraciones no lo permiten. ¿Reformamos también la Constitución para decir que el rey "propondrá o no un candidato a la Presidencia del Gobierno"? En ocasiones, la reducción al absurdo es un buen profiláctico contra un reformismo desaforado.

Otra de las propuestas que ha surgido es la del "establecimiento de un plazo que hoy no existe para que el jefe del Estado proponga al primer candidato a la Presidencia del Gobierno" ${ }^{40}$. No me parece una buena idea. En primer lugar porque, como he dejado claro anteriormente, estoy en contra de caer en el reglamentismo constitucional. Pero, y esto me parece más importante, porque la versatilidad y el carácter lábil y proteico de los supuestos de hecho que puedan darse como consecuencia de los resultados electorales desaconsejan encorsetar con rígidos plazos constitucionales lo que frecuentemente necesita tiempo para encajarse. Dos ejemplos. Tras las elecciones celebradas en 1996 fue necesario más tiempo del que venía siendo habitual (tanto en las consultas como en la celebración de la sesión de investidura) hasta que el ganador de las elecciones, que obviamente no tenía la mayoría absoluta, recalculó la verdadera talla de su eventual socio y descubrió las bondades del plurilingüismo. Desde la noche electoral hasta la investidura transcurrió un periodo necesario al que plazos estrictos le hubieran venido francamente mal. Más evidente todavía fue lo acaecido tras las elecciones de junio de 2016, en las que el partido más votado obtuvo 134 escaños. Después de un primer debate de investidura fallido en el mes de julio fue preciso que el principal partido de la oposición implosionara, que se obligara a renunciar a su secretario general y presidente del grupo parlamentario, que se nombrara una gestora, que el portavoz del grupo cambiara manifiestamente de posición entre los debates (del "no es no" a la abstención), y que el grupo tuviera quince votos contrarios a la posición oficial para que el candidato pudiese finalmente ser investido el 29 de octubre de 2016, en segunda votación y al límite del plazo constitucional. Habían transcurrido más de cuatro meses desde las elecciones, es cierto. Pero algunas cosas, por pequeñas

40 (Blanco Valdés, 2017: 92). El autor lo justifica así: "un plazo cuya necesidad no procede, a mi juicio, de la eventualidad de que el monarca pudiera tener por propia la voluntad de retrasar tal propuesta, una hipótesis que en la actualidad me parece sencillamente inverosímil, sino de la posibilidad que hoy tienen en sus manos los partidos para retrasar sin límites un acuerdo sobre la base del cual pueda el jefe del Estado proceder según lo previsto en el apartado $1^{\circ}$. del art. 99 de la CE”. 
que sean, requieren sus trámites y su tiempo. Con la fórmula a la que antes me he referido hubiera sido simplemente imposible.

También se ha afirmado que "podría llegar a ser saludable, en defensa de la institución de la Corona, que la facultad de propuesta pasara a manos del Presidente del Congreso" ${ }^{\text {". No }}$. comparto esta posibilidad. La Corona ha demostrado saber defenderse muy bien -al menos en esta cuestión-y, además, visto el ejercicio de la facultad presidencial para fijar la fecha del debate de investidura, me quedo, de lejos, con la fórmula constitucional. Precisamente, en estos cuatro últimos años, un rey "novato" ha demostrado ejercer con autoridad y altura de miras las facultades que le atribuye el artículo $99 \mathrm{CE}$. Si ha habido problemas, no han tenido nunca su origen en la Corona.

4.2. En punto a la previsión del artículo 99.2 hay que tener en cuenta que la fijación de la fecha del debate de investidura corresponde a la Presidencia del Congreso, conforme a la previsión del artículo 170 de su Reglamento. En ocasiones, esta convocatoria ha sido inmediata a la recepción de la propuesta regia. En otros casos, el lapso ha sido mayor. En este último supuesto, lo que sucedía es que el candidato no tenía cerrados los apoyos en el momento de ser propuesto. De ahí que un uso ponderado de este margen por el presidente del Congreso sea capital para garantizar el buen fin de la candidatura. También esta flexibilidad ha sido criticada por un sector de la doctrina ${ }^{42}$. Reitero una vez más que llenar de plazos la Constitución como si fuera una ley de procedimiento me parece una mala idea, amén de que su existencia hubiera podido abortar Gobiernos que se mostraron relativamente sólidos, como fue el caso de la primera legislatura de Aznar.

4.3. Por su parte, también se han alzado voces frente a la exigencia de obtención de mayorías, absoluta o simple, requerida en el artículo $99.3 \mathrm{CE}$, acompañadas, claro está, de sus correspondientes propuestas de reforma. Ya me he referido a la malograda oferta del candidato Sánchez en 2019. Sin ser demasiado claro ni concreto en su planteamiento, es evidente que la referencia a los gobiernos municipales y a

41 (López Rubio, 2017: 171). Tesis todauía más acentuada en Aragón Reyes (2017: 23) "De ese modo el Presidente del Congreso se convertiría a lo largo de todo el proceso de propuesta del candidato en el verdadero mediador". Bien es cierto que poco después señala el autor que "una condición para que el Presidente del Congreso desempeñase ese papel fundamental es que ese cargo lo ocupe una persona respetada por todos los grupos de la Cámara, caracterizado por su solvencia, neutralidad y no sometimiento a instrucciones de partidos". Sorprende que se tenga por viable el cumplimiento de estas condiciones en un trabajo que parte de la clara y radical desconfianza, muy motivada por su autor, respecto del comportamiento de las fuerzas políticas en la actual situación. Para un perfil de las tareas de la Presidencia de la Cámara: Alba Navarro (2018).

42 "A esos cambios en el art. 99 de la CE en su actual redacción debería añadirse el consistente en establecer otro plazo, de no más de cinco días desde la propuesta del rey, para que él o los candidatos a presidente acudiesen a la Cámara a solicitar su confianza" (Blanco Valdés, 2017: 93). El autor pone como ejemplos la investidura de Aznar en 1996 y la fallida de Sánchez en febrero-marzo de 2016. Ya he explicado previamente las causas de mi discrepancia. En ningún caso me parecen plazos excesivos. Pasar de la imprecación de la noche electoral a recabar el apoyo, y más aún, a obtenerlo, lleva su tiempo. 
"muchos estatutos de autonomía" indican que estaba pensando en lo que expresó gráficamente con un lema: "con una votación, basta" ${ }^{3}$. También en la doctrina se han hecho sugerencias parecidas ${ }^{44}$.

A riesgo de parecer demasiado reiterativo, me atrevo a señalar que tampoco me parece una gran solución. La Constitución parte de la obtención de la confianza por un concreto candidato y no de la elección entre varios. Entiendo perfectamente la prevención de repetir elecciones en bucle y, desde luego, Israel no es mi modelo preferido. Pero el recurso al arbitraje de la ciudadanía, sobre el que luego volveré, cuando las fuerzas políticas bloquean la gobernabilidad no me parece una mala solución en última instancia. Además, si se aceptara el cambio al que me refiero entiendo que también habría que modificar el régimen de la moción de censura constructiva del artículo $113 \mathrm{CE}$. Y eso porque está diseñada como el reverso de este modelo. No me parece aceptable que sea mucho más fácil de lo que ya es ser elegido y se mantenga idéntica dificultad para la remoción. El sistema debe ser contemplado en su conjunto.

Lo más llamativo es que la realidad ha desmentido con datos concluyentes que el problema esté necesariamente en el umbral de las mayorías requeridas por la Constitución. Para muestra, un botón. El 28 de abril de 2019 se celebran elecciones generales. El Partido Socialista junto al PSC obtiene 123 escaños; el Partido Popular y sus aliados, 68; Ciudadanos, 57, y Unidas Podemos y su vertiente catalana, 40. De esta manera se abrían varias posibilidades de gobierno. La más evidente, numéricamente hablando, era la suma del Partido Socialista con Ciudadanos, que suponía 180 escaños, claramente por encima de la mayoría absoluta. El resto de opciones pasaban siempre por el Partido Socialista, bien con el Partido Popular -posible, aunque poco imaginable- bien con Unidas Podemos y otros partidos de corte nacionalista.

Dado que varias opciones ofrecían las mayorías requeridas, quedó claro que el problema no era matemático, sino puramente político. Descartado de raíz que el PP le devolviera al PSOE el "favor" de 2016 al que antes me referí y que tan alto coste tuvo para este último, las miradas se volvieron hacia Ciudadanos. Se afirma con profusión que este partido nació en Cataluña como un modo de combatir, desde perspectivas no nacionalistas, la hegemonía política del nacionalismo catalán y, en general, cualquier otro. En sus filas y en su entorno (mediático y doctrinal) eran reiteradas las quejas contra las políticas "extractivas" a las que antes me he referido. En su salto a la política nacional tuvo una trayectoria ascendente, que alcanzó su mejor resultado en las elecciones de abril de 2019, situándose como la tercera fuerza del Congreso. Pues bien, en el momento en que estaba en su mano terminar 
tranquilamente con la "extracción de recursos" tan criticada, sus líderes decidieron pelear por un espacio tradicionalmente ocupado y en ese momento saturado. El partido que necesitaba el apoyo de Ciudadanos no era Junts per Catalunya ni el PNV ni Esquerra Republicana. Mucho menos Bildu. Omitiendo valoraciones personales, me remito al dato de que en las elecciones de noviembre de ese año (por causa de la disolución automática del artículo 99.5 CE) el Partido Socialista perdió más de 700.000 votos y tres escaños y Ciudadanos se dejó en el camino más de dos millones y medio de votos y 47 de sus 57 escaños. El electorado castigó a ambos partidos. ¿A cada uno en proporción a su responsabilidad?

¿Qué norma constitucional impedía un gobierno estable, duradero y no sometido a exigencias de partidos de ámbito no estatal?

4.4. El artículo 99.4 permite al rey tramitar propuestas sucesivas si el primer candidato no obtiene la confianza de la Cámara. Cayó en desuso desde la aprobación de la Constitución hasta hace poco. No obstante, ha demostrado su sentido y utilidad, en especial el año 2016. Como es evidente, nada impide que la nueva propuesta recaiga en el mismo candidato cuya investidura no fue alcanzada previamente. Otro ejemplo más de cómo las normas constitucionales, incluso aquellas que parecían ociosas, son sumamente útiles y flexibles cuando la realidad presenta sus demandas ${ }^{45}$.

4.5. El artículo 99.5, que prevé la disolución de las Cámaras y la convocatoria de elecciones si no se obtiene la confianza para ningún candidato, constituyó también durante muchos años un "fondo de armario" constitucional del que nadie parecía acordarse. Se ha venido considerando una suerte de disolución-sanción en la medida en que implica la pérdida del escaño para todos los parlamentarios por haber fracasado en su primera tarea: ser capaces de crear un gobierno. En el caso de los senadores, se trata de una sanción por culpas ajenas toda vez que no depende de ellos la designación del presidente del Gobierno ${ }^{46}$.

Hasta 2016, este artículo parecía totalmente superfluo. Desde entonces se ha empleado dos veces. En mayo de 2016 y septiembre de 2019. En ambos casos, tras la disolución, el partido mayoritario confirmó su posición aunque, mientras el PP reforzó su posición anterior en 2016, el PSOE bajó levemente en 2019.

45 Revenga Sánchez, por su parte, considera que se omitió el presupuesto constitucional de efectuar "otras propuestas" en el proceso que llevó a la investidura de Rajoy en 2016 (2017:114).

46 (Revenga Sánchez, 2004: 517 y 2017: 118), se manifiesta contrario a la disolución automática del Senado. Esta, que se acordó tras un cambio en la tramitación del texto constitucional, me parece bastante coherente si tenemos en cuenta que, pese a la posición disminuida del Senado en el bicameralismo español, la Cámara Alta sigue ostentando poderes importantes que le permiten facilitar el bloqueo político en caso de mayorías diferentes entre la Cámaras. Así sucedió en 1995 tras las elecciones autonómicas y el cambio de mayoría en el Senado y recientemente en 2018 tras el triunfo de la moción de censura con los escenarios de estabilidad presupuestaria. En ambos casos, con el Partido Popular mayoritario en el Senado. 
La previsión constitucional contenida en el artículo 99.5 parte de un dies a quo (dos meses a partir de la primera votación de investidura) que, como hemos visto, puede no producirse. De ahí que la doctrina haya señalado la necesidad de reformar este aspecto del texto constitucional ${ }^{47}$.

Siendo deseable una solución a lo que, en este caso sí, es una laguna evidente, la sugerencia de introducir un dies a quo claro y operativo es más que razonable. Me permito, sin embargo, recordar que el precepto ha sido empleado en dos ocasiones con total normalidad constitucional. En ambos casos, tras la celebración de esas elecciones se pudo constituir un Gobierno. Es decir, nunca se ha entrado en el bucle de elecciones concatenadas que otros países han sufrido. Si después la duración de la legislatura no ha llegado a término, no ha sido por la redacción o el contenido del artículo 99.5, sino por otras circunstancias directamente derivadas de la fragmentación política. También es cierto que el artículo 99.5 es un precepto al que no conviene acostumbrarse con naturalidad. No es bueno su abuso por lo que implica. Como el artículo 155 o el 116, por otra parte.

5. "Desde la letra de la Constitución, el Gobierno puede ser depuesto y sustituido por el Congreso de los Diputados si se presentase una moción de censura y esta obtuviese la mayoría de los votos, pero, en la realidad política, nunca se ha manifestado de tal modo".

Esto escribía la profesora González-Hernández en el primer trimestre de $2018^{48}$. Pocos meses después, Pedro Sánchez era investido presidente del Gobierno tras triunfar una moción de censura. No es cuestión de entrar a valorar las dotes proféticas de la autora. En realidad, no estaba diciendo nada distinto a la inmensa mayoría de la doctrina ${ }^{49}$.

Pero semejante creencia no era correcta ni siquiera cuando las escasas mociones de censura presentadas fracasaban una tras otra. Ya en ese momento tenían una función de exposición pública y política nada desdeñable si se sabía utilizar adecuadamente. Simón Yarza, usando las categorías de Merton, la calificaba de función latente ${ }^{50}$.

Ha sido, sin embargo, el éxito de la moción de censura de 2018 lo que ha abierto la espita de las críticas y la atención sobre la institución. $\mathrm{O}$, al menos, respecto al modo en que se ha manifestado en esta ocasión. Así, se ha leído que carecía de un programa común de

47 (Blanco Valdés, 2017: 93); (García-Escudero Márquez, 2018: 96); (López Rubio, 2017: 174). Este último detalla el esperpéntico -y preocupantecaso del "tamayazo" en la Asamblea de Madrid el año 2003 y da cuenta del dictamen del Consejo de Estado emitido el 26 de junio de 2003 sobre este particular.

48 (González-Hernández, 2018: 200).

49 Por todos, Aragón Reyes, citado por Mateos y de Cabo (2017: 179).

50 (Simón Yarza, 2015: 98): "En efecto, la moción de censura constructiva puede ser utilizada para forzar una confrontación entre el Presidente del Gobierno y el candidato propuesto que, en ciertos casos, sería inviable de otra manera. De hecho, el uso que en España se ha hecho de la moción constructiva obedece básicamente a esa función latente, no directamente perseguida por el constituyente. Felipe González buscó -y consiguiórealzar su propia figura política frente a un debilitado Suárez, y Hernández Mancha forzó un debate que, de otro modo, no se habría producido". 
gobierno, que no era constructiva sino destructiva, que había una heterogeneidad inaceptable entre sus votantes, que tenía una simple virtualidad instrumental, etcétera.

No es el objeto de una publicación de esta naturaleza contestar políticamente a dichas críticas. Interesa, en cambio, verificar si determinadas opiniones doctrinales alineadas con -o alimentadoras de- las opiniones anteriores son ciertas. Es decir, si lo que sucedió se ajustó a la Constitución. Acepto como verdad incontestable que el constituyente nunca fue un entusiasta de las mociones de censura por su empeño en garantizar la estabilidad gubernamental. No obstante, la recogió con plenitud en el artículo 113. Y, por consiguiente, es un medio tan constitucional como cualquier otro para hacer surgir un gobierno, aunque quizá algo más traumático. Por tanto, las frecuentes apelaciones a la falta de legitimidad de un gobierno por el hecho de nacer de una moción de censura me parecen, estas sí, difícilmente compatibles con la Constitución, sin dejar de reconocer el amplio espectro del derecho a la libertad de expresión.

El artículo 113 CE señala con nitidez el objeto de la moción de censura: "exigir la responsabilidad política del Gobierno". Este objetivo está recogido con tanta amplitud que dificulta notablemente reducirlo a supuestos de hecho muy concretos ${ }^{51}$. Un cambio esencial en la política de un gobierno puede ser motivo de alegría para la oposición, en ocasiones. Pero no hace falta tener mucha imaginación para pensar que involucrar a un país en una guerra impopular, crear serios problemas de orden público con sus políticas u otros supuestos análogos son motivos de pleno fundamento constitucional para presentar una moción de censura. Y también, cómo no, la corrupción. Explicando la virtualidad de la rendición de cuentas (y, en este caso sí, con una capacidad profética extrema) señalaba González-Hernández en los primeros meses de 2018:

Una de las claves estaría, pues, en desincentivar la ventaja que supondrían las conductas corruptas, lo que nos conduce nuevamente al mismo punto, si bien, por otro camino: el de los atolones de cierta irresponsabilidad que pueden seguir presentes en normas constitucionales y/o legales que impiden garantizar una verdadera rendición de cuentas. La calidad de la democracia requiere de un importante grado de confianza de los ciudadanos en sus instituciones, lógica consecuencia de una opinión pública crítica y vigilante y con elevadas exigencias éticas. Y es que la corrupción política repugna la conciencia cívica. Tiene un efecto demoledor sobre la legitimidad del sistema y produce efectos negativos en cadena (...) Puede calificarse, por ello, de cáncer de la democracia ${ }^{52}$.

A diferencia de lo previsto en el artículo 99 CE para la investidura, la Constitución guarda silencio sobre la exigencia de que el candidato incluido en una moción de censura presente un programa. No es uno de los requisitos de tan complicado proceso. Solo desde la mímesis con el mencionado artículo 99 debe entenderse la exigencia del

51 "En definitiva, la Constitución no exige como supuesto de hecho para poner en marcha una moción de censura la desuiación por parte del presidente del programa expuesto en su investidura”. (López Rubio, 2017: 173).

52 (González-Hernández, 2018: 206). 
artículo 177.1 del Reglamento del Congreso. Exigencia que, reitero, no tiene naturaleza constitucional $^{53}$.

Ello nos conduce a preguntarnos si es compatible con la Constitución una moción de censura instrumental. En este caso, con el objetivo de convocar elecciones. Coincido plenamente con Simón Yarza cuando señala que "Honestamente, pienso que el planteamiento de una moción instrumental no se opone necesariamente al espíritu de la Constitución” ${ }^{4}$. En el caso que nos ocupa, si el señor Sánchez cayó en la tentación de extravasar la instrumentalidad de su moción de censura ${ }^{55}$, la realidad política vino a ponerle en su sitio y, tras el fracaso para aprobar los Presupuestos Generales del Estado, se vio obligado a convocar elecciones.

La funcionalidad de la moción puede operar también en otro sentido. En determinadas circunstancias, una moción de censura puede desbloquear una situación política viciada por las causas que sean. No es necesariamente disfuncional ${ }^{56}$. Aun más, como se ha señalado acertadamente: "En un parlamento con varios partidos de ideologías inconciliables y extremas, el carácter constructivo de la moción tiende a producir el efecto estabilizador que el sistema de partidos niega" ${ }^{\text {"7 }}$.

Lo que signifique "ideologías inconciliables y extremas" es bastante anfibológico. Me permito recordar, no obstante, cómo empezó la legislatura y lo que tuvo que acaecer para poder investir presidente al señor Rajoy en 2016. Quizá por ahí encontremos explicaciones a muchas cosas.

Concluía Simón Yarza su trabajo de 2015 haciendo prospección de la situación española de ese momento y era bastante concluyente cuando afirmaba que: "la moción de censura constructiva podía demostrarse en el futuro como una regla eficaz para impedir la inestabilidad política"58.

Cuatro años más tarde, el mismo autor, tras efectuar un brillante repaso de la teoría de la moción de censura, concluye tajantemente: "pienso que la moción de censura del Sr. Sánchez no se llevó a cabo simplemente al margen, sino en franca oposición al espíritu de la moción constructiva"59.

53 (Simón Yarza, 2109: 123), afirma, respecto a la presentada por el Grupo Socialista en mayo, que: "Solo formalmente puede calificarse la 'hoja de ruta' propuesta por el Sr. Sánchez, a mi modo de ver, como un programa de gobierno".

54 (Simón Yarza, 2019: 127). Dicho sea con todas las reservas que siempre me suscita la mención al "espíritu" en los análisis jurídicos.

55 Reconociendo poco implícitamente este carácter, el candidato Sánchez ofreció al presidente Rajoy retirar la moción si este dimitía. Más claro, agua.

56 “...la mayoría exigida en nuestra Constitución para derribar al anterior Gobierno permite una investidura automática de un nuevo presidente, por lo que no supone un bloqueo institucional, ya que tanto el antiguo como el nuevo Gobierno están garantizados, es decir, que favorece la pervivencia del antiguo mientras no prospere un nuevo Ejecutivo". (Mateos y de Cabo, 2017: 162).

57 (Simón Yarza, 2015: 99). Señala poco después que "En un régimen parlamentario capaz de producir regularmente sólidas mayorías de gobierno, sin embargo, este mecanismo deja de cumplir una función estabilizadora y se convierte en una especie de parapeto que blinda al gobierno permitiéndole, una vez investido, desatender los compromisos contraídos con sus socios de coalición sin perder su status".

58 (Simón Yarza, 2015: 108)

59 (Simón Yarza, 2019: 133) 
Curiosamente, soy de la opinión de que su muy documentado artículo aporta todos los elementos para sostener la interpretación contraria o, al menos, para justificar su plena constitucionalidad. Lo que está en la base de esa afirmación -el autor no lo oculta- es la clásica teoría del fraude jurídico ${ }^{60}$. ¡Cómo no reconocer la antigüedad de la teoría y su virtualidad! Pero acto seguido señaló que la posibilidad de constatar su existencia es una de las tareas más ímprobas de la dogmática jurídica (para los opinadores políticos todo es más sencillo). De hecho, ha sido casi siempre uno de los "recursos de última instancia” al que se apela cuando el arsenal está agotado. De ahí mi instintiva desconfianza hacia su invocación.

Por ello, tiendo más bien a pensar -hecho reconocido incluso por muchos de los que criticaron la operación política- que la instrumentación "formal" de la moción de censura, así como su ulterior tramitación, fueron irreprochables. Su aprobación buscaba -con éxito interpretable, es cierto- el desbloqueo de una situación en la que se encontraba un gobierno -minoritario, no lo olvidemos- que, cercado por los problemas antes apuntados, había perdido el crédito de la opinión pública. El Partido Popular entró en la legislatura de 2016 con 134 escaños y en la de abril de 2019, subsiguiente a la moción de censura, le quedaban 68. La pregunta sobre el cuándo es más propia de la magistral pluma de Vargas Llosa.

\section{CONCLUSIONES}

Vivimos tiempos de cambios. Desaparecen o se transforman paradigmas que han funcionado largo tiempo. Aparecen nuevas realidades. Y siempre que sucede esto, hay mucha gente para la que todo tiempo pasado fue mejor. Se crea inseguridad ante la extensión y profundidad de los cambios. Pero no es cierto: cualquier tiempo pasado no fue necesariamente mejor; fue, simplemente, diferente.

Pertenezco a la primera promoción de licenciados en Derecho que salió de la Facultad con la Constitución de 1978 debajo del brazo. Desde esta veterana militancia constitucional, contemplo con satisfacción que aquellos que hablaban sin especial cariño del "régimen del 78" empiezan a apreciar las bondades de la Constitución. Aunque sea a trozos y de manera parcial. Por algo se empieza. Pero muchos estábamos desde el principio en este Mediterráneo al que sigue llegando gente que siempre es bienvenida. Por eso creo vivamente en la virtualidad y vigencia del texto constitucional.

Puede decirse, de un modo bastante aproximado, que en nuestra sociedad la aplicación del texto constitucional ha tenido lugar en dos periodos que coinciden casi exactamente con los reinados de Juan Carlos I y Felipe Vl. En ambos la Constitución española ha dado muestras de una prodigiosa flexibilidad, que apenas ha requerido 
de reformas formales. El mismo texto ha funcionado en realidades sociales muy diferentes y ha servido incluso en momentos de gran desafío al propio sistema político y constitucional.

Lo que muchos interpretan como "desajustes" del sistema no traen causa, a mi entender, de problemas propios de nuestro texto constitucional. Responden más bien a cambios profundos en la estructura social. Unos son lógica consecuencia del transcurso de un tiempo que ya va siendo largo desde su aprobación en 1978. Otros han sido propiciados por factores de graves crisis económicas y sociales a las que no son ajenos fenómenos de dimensión mundial. Y otros son manifestaciones recurrentes de lo que en nuestra larguísima historia como nación nunca fuimos capaces de resolver del todo.

Frente a estos retos, la Constitución ha aportado soluciones jurídicas en todos y cada uno de los casos. El cambio radical del sistema de partidos, la sucesión en la jefatura del Estado, el desafío secesionista, la pandemia de la covid-19, etcétera, han encontrado siempre una respuesta en el texto constitucional. Otra cosa es que la gestión política de esos retos haya estado a la altura de las circunstancias.

Es muy tentador, cuando se tiene una larga experiencia, advertir peligros por doquier. Incluso si estos son contradictorios entre sí. Así se pasa, por ejemplo, de advertir contra el riesgo de que el Parlamento sea un departamento legislativo del Gobierno a prevenir pocos años después contra el temor de que lleguemos a un "parlamentarismo de asamblea" ${ }^{\prime 1}$.

Ni una cosa ni la otra, a mi parecer. El acomodamiento de una sociedad diferente y un sistema de partidos muy distinto al mismo texto constitucional requiere tiempo, paciencia y tanteos.

No me manifiesto contrario a abordar reformas en la Constitución. Pero para que tengan sentido es preciso que nos aseguremos de que el resultado de la reforma propuesta sea realmente funcional y no una mera transposición de aquello que ideológicamente nos parece más ajustado a nuestras propias convicciones. España es un país que tradicionalmente ha tendido a intentar solucionar problemas con la aprobación de nuevas normas sin haber intentado extraer previamente todas las potencialidades de las que ya estaban en vigor. Cuando leo propuestas sobre reformas constitucionales consistentes en introducir plazos, perfilar detalles, en resumidas cuentas, en hacer una constitución "reglamentista", siempre releo el título X de la Constitución y vuelvo a constatar qué fácil es proponer una reforma en un papel y qué difícil es llevarla a cabo por el procedimiento establecido en la propia Constitución. Esto, sin entrar en la vertiente política que implica siempre la tensión inherente a una reforma constitucional, cuando, como he indicado, nunca ha faltado respuesta normativa a un problema planteado. 
Muchas de las reformas que he analizado en este trabajo reconocen abiertamente que el problema que pretenden solucionar es producto de un sistema político mucho más fragmentado. Fragmentado me parece un vocablo muy elegante para referirse al clima político que vivimos desde hace un tiempo. ¿De verdad pensamos que es este el mejor momento para proponer reformas constitucionales o legales como las anteriores?

Llevo mucho tiempo convencido de que en la actual situación política de España hubiera sido imposible aprobar una constitución tan avanzada, innovadora y, en el fondo, progresista como la que fueron capaces de alumbrar los constituyentes de 1978.

Y, sobre todo, y volviendo a mi escepticismo sobre la "cientificidad" social de los juristas, recojo aquí la cita de Simón Yarza que, al referirse a las situaciones de ingobernabilidad, reconoce expresamente: "Esto no siempre se puede garantizar a través de reglas jurídicas, dado que la fragmentación ideológica de la sociedad se resiste, en ocasiones, a la simplificación a través del Derecho" ${ }^{2}$.

No puedo estar más de acuerdo con esta idea. Por ello creo que las reformas analizadas no son la vacuna a los problemas, falsos o reales, detectados por la doctrina. Salvo la fijación de un dies a quo en el artículo 99.5, no encuentro suficiente fundamento en ellas. $Y$, sinceramente, no me parece que esa sensata reforma tenga en este momento el mejor caldo de cultivo. 


\section{BIBLIOGRAFÍA}

Alba Navarro, M. (2018). Reflexiones sobre la Presidencia de las Cámaras. Revista de las Cortes Generales, (103), 273-293.

Áluarez Vélez, M. I. (2016). La investidura del Presidente del Gobierno y las similitudes y diferencias de las investiduras de los Presidentes de los ejecutivos autonómicos. Revista General de Derecho Constitucional, (22).

Aragón Reyes, M. (2017). Legislatura fallida e investidura conuulsa. Análisis y consecuencias. Revista Española de Derecho Constitucional, (109), 15-34.

Bar Cendón, A. (1998). Comentario al artículo 99 de la Constitución. En O. Alzaga (Ed.). Comentarios a la Constitución Española de 1998. Madrid: Edersa.

Blanco Valdés, R. L. (2017). El año que vivimos peligrosamente. Del bipartidismo imperfecto a la perfecta ingobernabilidad. Revista Española de Derecho Constitucional (109), 63-96.

García-Escudero Márquez, P. (2018). Un nueuo parlamento fragmentado para los 40 años de la Constitución. Revista de derecho político, (101), 67-98.https://doi.org/10.5944/ rdp.101.2018.21951

García-Escudero Márquez, P. (2019). Balance de la moción de censura constructiva en un parlamento fragmentado. Teoría y Realidad Constitucional, (44), 67-98.

González-Hernández, E. (2018). El modelo de responsabilidad del Gobierno en la Constitución de 1978 o jugar a las siete y media. Revista de Derecho Político, (101), 183-214.

López Rubio, D. (2017). La investidura del Presidente del Gobierno: un análisis a la luz de la experiencia reciente. Eunomia, Revista en Cultura de la legalidad, (13), 159-181.
Mateos y de Cabo, O. (2017). La elección parlamentaria del Presidente del Gobierno en España: análisis normativo, estabilidad institucional y propuesta de reforma del artículo 99.5 de la Constitución española. Revista Española de Derecho Constitucional, (111), 155-184.

Nohlen, D. (2013). Controversias sobre los sistemas electorales y sus efectos. Revista Española de Ciencia Política, (31), 9-39. Recuperado de https://recyt.fecyt.es/index.php/recp/article/ view/37573

Revenga Sánchez, M. (2004). Veinticinco años de formación del Gobierno. Revista de Derecho PolítiCo, (58-59), 505-522.

Revenga Sánchez, M. (2017). La funcionalidad del artículo 99 de la Constitución. Ante el caso de un resultado electoral fragmentado: ¿mejorar su aplicación o proponer su reforma? Revista Española de Derecho Constitucional, (109), 97-120.

Sánchez Muñoz, O. (2017). El fin (momentáneo) del bipartidismo en España: análisis de los resultados electorales de 2015 y 2016. Revista española de derecho constitucional, (109), 237-60. https://doi org/10.18042/cepc/redc.109.09

Simón Yarza, F. (2015). La moción de censura: ¿constructiva u "obstructiva"? Revista Española de Derecho Constitucional, (103), 87-109.

Simón Yarza, F. (2019). De la investidura conuulsa a la moción de espíritu destructivo. Revista Española de Derecho Constitucional, (116), 11-136.

Torres del Moral, A. (2009). La reforma del sistema electoral o la cuadratura del círculo. Revista de Derecho Político, (74), 51-111. 